\title{
Experimental Study of the Influence on the Residual Fatigue Life of 45 \# Steel Fatigue Damage Specimens
}

\author{
WANG Ping ${ }^{1, a}$, YANG Rong ${ }^{2, b}$ and TIAN Jifeng ${ }^{1, c}$ \\ ${ }^{1}$ College of Civil Engineering and Mechanics, Yanshan University, Qinhuangdao,China 066004 \\ ${ }^{2}$ The State key Laboratory of Nonliner Mechanics, Institute of Mechanics, Chinese Academy of \\ Sciences, Beijing, China 100080 \\ âwangpin0721@163.com, byangr@Inm.imech.ac.cn, 'tianjifeng123@126.com
}

Keywords: fatigue; damage; fatigue life; repair; pulse discharge.

\begin{abstract}
In this paper, the fatigue life of the 45 \# steel specimens is tested. Two groups of fatigue damage specimens are prepared for the experimental study. Their fatigue cycles respectively reached $80 \%$ and $90 \%$ of the fatigue life tested. The repairing experiments to the two groups' specimens by the high voltage pulse discharge are finished. After these repairing experiments, the residual fatigue lives of the two group specimens repaired are tested. The results show that the residual fatigue lives of the specimens are improved greatly. The total fatigue lives of the specimens have been increased at least $160 \%$ of the fatigue life tested.
\end{abstract}

\section{Introduction}

Metal components failure due to fatigue damage and fatigue crack is a widespread phenomenon in practical applications of current military, navigation, aviation, aerospace, nuclear industry, energy, chemicals and machinery industries. If certain measures can be taken to control the damage, even make the original damage healed, the service life of fatigue components will be extended. Therefore, the interest of research on fatigue damage healing of metal component has attracted many scholars and engineers. Looking for an effective method to repair fatigue damage or fatigue crack has important theoretical and practical value.

Some references can be found of the research of improving materials fatigue and fracture life. ZHOU et al investigated the influences of the electric pulse current on the quenching crack of 45 steel [1]. HAN et al studied the repair phenomenon at high temperature of cracks in 20MnMo steel and its microstructure change [2]. SHEN et al just simply illustrated the possibility for improving fatigue property of low carbon steel using electro pulse current, but no details in their research procedure [3]. XIAO et al investigated the recrystallization of fatigued copper single crystals and the dislocation behaviors under electro pulsing $[4,5]$. LV et al observed the microstructure of the fatigued heat rolled $30 \mathrm{CrMnA}$ steel after treated by electro pulse current [6]. Du et al researched the repairing effect of damaged materials $40 \mathrm{Cr}$ steel by intermediate annealing and the quenched [7,8]. Li and Qiao et al investigated the damage repairing of the LY12CZ aluminum alloy specimen with thickness $2 \mathrm{~mm}$ by pulse direct current, and the resistance of received, fatigued and repaired specimens was measured by electric bridge, respectively. They also observed the microstructure change by optical microscope and transmission electron microscope [9]. J. Ahmad et al investigated the thermal fatigue and corrosion fatigue in heat recovery area [10]. H.Q. Lin, Y.G. Zhao et al investigated The fatigue crack propagating behaviors of cast hot working die (CHWD) steel untreated and treated by an electric current in the intermediate stage of thermal fatigue[11]. V.V. Levitin and S.V. Loskutov investigated how the power current pulses influence the fatigue resistance, the surface stresses, and the microstructure parameters of titanium alloy[12]. J.E. Rodriguez-Sanchez, W.D. Dover and F.P. Brennan defined a new fatigue crack repair concept as 'short repair', using a short repair to extend the fatigue life of cracked welded connections[13]. 
Low carbon steel is widely used in industry as shafts or connection type parts, such parts are often brought into fatigue damage. In this paper, the fatigue life of the 45 \# steel specimens is tested by the fatigue life test. Two groups of fatigue damage specimen are prepared through fatigue experiment, and their fatigue cycles respectively reached $80 \%$ and $90 \%$ of the tested fatigue life. The repaired experiments to the two group's specimen by the high voltage pulse discharge have been done. After these experiments, the residual fatigue lives of the two group repaired specimens are tested. The results show that, the residual fatigue lives of the specimens are improved obviously after repaired by pulse discharge.

\section{Experimental study}

\subsection{Preparation of specimens}

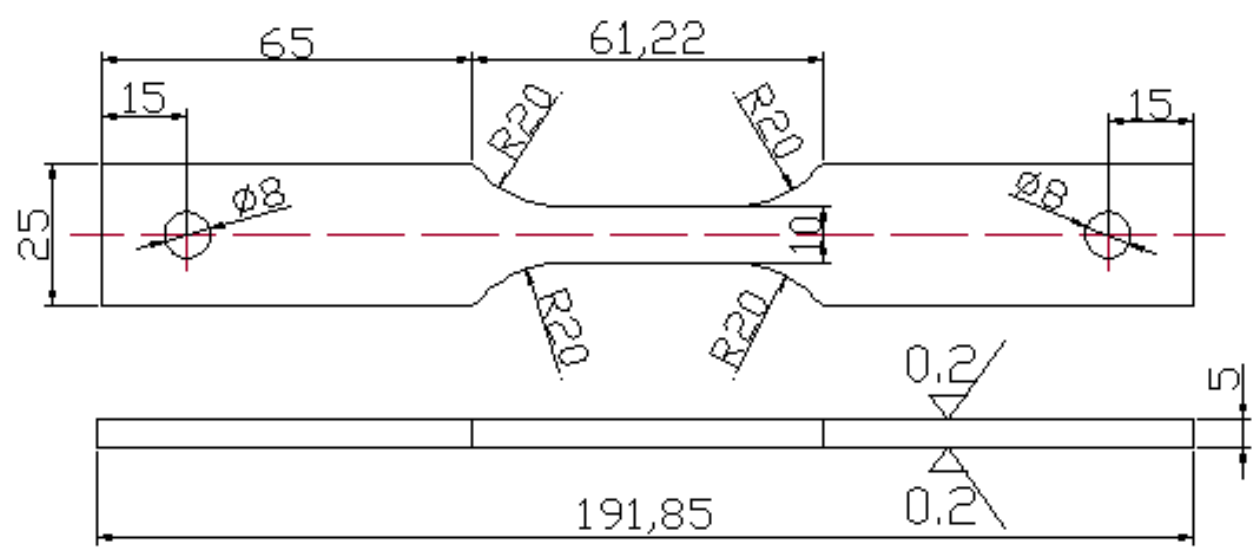

Figure 1. The specimen design and the photograph of a specimen

The material of the specimen is $45 \#$ low carbon steel. The specimens are cut using wire cutting machine on the same 45\# low carbon steel plate and polished using sand paper. Specimen design of a specimen is shown in Figure 1.

\subsection{The experimental equipment and conditions}

The fatigue test equipment is EHF-EM electro-hydraulic servo fatigue test machine made in Japan. The tester is multi-function material testing machine with digital control system. It is mainly used for static, fatigue and fracture toughness and other mechanical performance test for the standard specimen. The fatigue test can be controlled by the stress fatigue or the strain fatigue test.

First, the tensile test is done to get the 45\#steel's yield limit. After that, according to the geometry size of specimen and the yield limit to determine the load of the fatigue test. The specific control conditions are as follow: the tensile-tensile fatigue test is to take a sine wave load force control mode, alternating frequency $\mathrm{f}=35 \mathrm{~Hz}, \mathrm{R}=0.1, \sigma \max =290 \mathrm{MPa}$, at room temperature.

\section{3 The fatigue life test and the fatigue damage specimen preparation}

In the fatigue test process, the load is controlled to keep the deformation of the specimen in the elastic range. The deformation of the specimen has fluctuation with the load changes. The specific test process is as follows: The fatigue test specimens are divided into three groups. There 
are four specimens in each group. The group A specimens is used to test the fatigue life $\mathrm{N}_{\mathrm{f}}$ under the setting load conditions. And thus the fatigue cycles of $90 \% \mathrm{~N}_{f}, 80 \% \mathrm{~N}_{\mathrm{f}}$ can be learned.

The group $\mathrm{B}$ and $\mathrm{C}$ specimens are used for fatigue damage specimens' preparation. Considering the practical significance of the fatigue damage components repairing, assume the fatigue load cycles of the fatigue damage components in the engineering practice are close to the fatigue life limit. The preparation condition is the same with the fatigue life test. The fatigue cycles are to reach $90 \%$ and $80 \%$ of the fatigue life $\mathrm{N}_{\mathrm{f}}$ tested respectively. Fatigue test records are shown in figure 2 . And then will be repaired in experimental study by high voltage pulse current discharge.

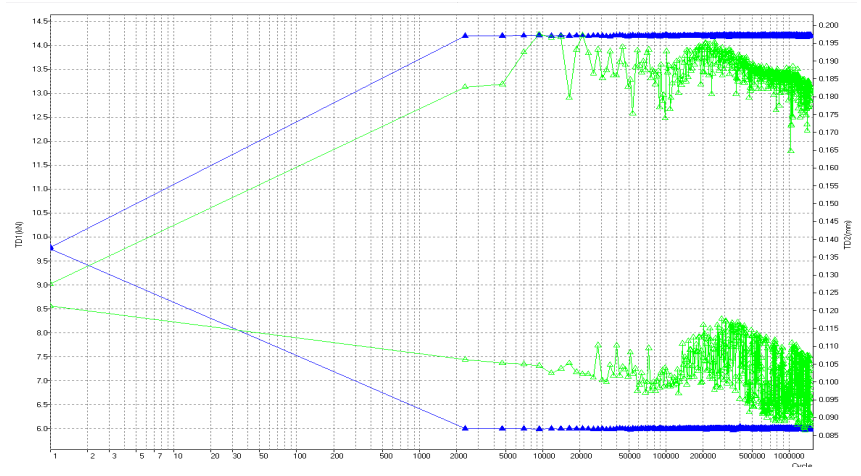

Figure2. The fatigue experimental recording chart

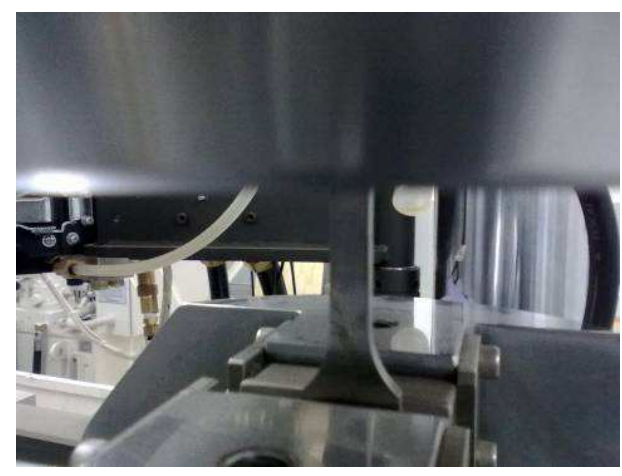

Figure3. Some weak protrusions which look like slip band

Fatigue test data is shown in table 1. During the experiment, it is observed that the fatigue fracture failure is due to a visible crack appeared suddenly on the specimen's surface, and then the crack expanded rapidly, until the fracture happened. From the appearance of the visible crack to the complete fracture, the fatigue cycles may almost be negligible compared with the total fatigue life, and there is not any obvious sign before the visible crack appears.

The following phenomena can also be observed in the experimental process, some weak protrusions which look like slip band similarly can be seen at the location of fatigue fracture at the surface of the group A specimen. And the similar phenomena can also be found on the surfaces of the group B and C specimen, but there is no any surface cracks observed. (See Figure3)

Table 1. Experiments and its data

\begin{tabular}{|c|c|c|c|c|c|c|}
\hline $\begin{array}{l}\text { specimen } \\
\text { group }\end{array}$ & Experiment 1 & $\begin{array}{l}\text { Fatigue cycles } \\
\qquad\left(\times 10^{4}\right)\end{array}$ & $\begin{array}{c}\text { Experiment } \\
2\end{array}$ & $\begin{array}{c}\text { Experiment } \\
3\end{array}$ & $\begin{array}{l}\text { Fatigue cycles } \\
\qquad\left(\times 10^{4}\right)\end{array}$ & $\begin{array}{l}\text { Total fatigue } \\
\text { cycles }\left(\times 10^{4}\right)\end{array}$ \\
\hline $\mathrm{A}$ & Fatigue life test & 167 & & & & 167 \\
\hline B & $\begin{array}{c}\text { Fatigue damage } \\
\text { preparation }\end{array}$ & 150 & $\begin{array}{c}\text { Repaired by } \\
\text { pulse } \\
\text { discharge }\end{array}$ & $\begin{array}{c}\text { Residual } \\
\text { Fatigue life } \\
\text { test }\end{array}$ & 120 & 270 \\
\hline C & $\begin{array}{c}\text { Fatigue damage } \\
\text { preparation }\end{array}$ & 135 & $\begin{array}{l}\text { Repaired by } \\
\text { pulse } \\
\text { discharge }\end{array}$ & $\begin{array}{l}\text { Residual } \\
\text { Fatigue life } \\
\text { test }\end{array}$ & 450 & 585 \\
\hline
\end{tabular}

\subsection{The repairing experiments and the remaining fatigue life test}

The equipment used to finish the repairing experiment for fatigue damage specimen using high-voltage pulse is ZL-2 high-voltage pulse discharge device self-developed. It has some characters like high energy storage, high power, short discharge cycle and 
automatic control. The high voltage pulse discharge device consists of the charging device, the main discharge circuit, the trigger circuit, the measuring device and the control loops.

According to the experimental research program, it needs to repair the fatigue damage specimens prepared by high voltage pulse discharge first, and then to do the remaining fatigue life test after repairing. Through these experiments for getting the aid of determining if the repair method is effective.

The repairing experiments for the groups $\mathrm{B}$ and $\mathrm{C}$ fatigue damage specimens using high voltage pulse discharge have been done with discharge equipment. The discharge voltage is 10,000 volts. The discharge time is 30-50 microseconds. After the repairing experiments, the specimens do not change significantly in appearance.

The remaining fatigue life for the repaired specimens under the same fatigue load has been tested. Its results show that the remaining fatigue life of the specimen increased significantly. The remaining fatigue life tested is given in Table 1 .

\section{Discussion}

According to the experimental study process, it is known that the initial fatigue test cycles of the groups $\mathrm{B}$ and $\mathrm{C}$ achieved $90 \%$ and $80 \%$ of the fatigue life respectively. It means that their remaining fatigue lives are $10 \%$ and $20 \%$ of the fatigue life tested in group A test. However, after the repairing by high voltage pulse discharge to the groups $\mathrm{B}$ and $\mathrm{C}$ specimens, the remaining fatigue life of the group B specimen reached 1.2 million fatigue cycles, about $75 \%$ of the fatigue life tested using the group A specimen. The remaining fatigue life of group $\mathrm{C}$ reached 4.5 million fatigue cycles, about $260 \%$ of the fatigue life. Thus, through comparing the remaining fatigue life before and after repairing we know that the high voltage pulse discharge repairing can really extended the remaining fatigue life of the fatigue damage specimen. And the repair effect is much better when the fatigue cycles reached the $80 \%$ of the fatigue life than reached the $90 \%$. In the other words, the remaining fatigue life of the specimen can be extended much longer when repairing at the fatigue cycles reached the $80 \%$ of the fatigue life than at the $90 \%$. Of course, since the specimen's number of the experimental study limited and the differences among each specimen, there may be a certain one-sidedness of the experimental results. It is still needed to make a large number of experimental studies. It is also needed to do the corresponding experimental research of many kinds of metal materials, in order to have better understanding the repair effect on the fatigue damage component by the pulsed high-voltage discharge.

It is found that the remaining fatigue life of the specimens of which the fatigue cycles reached the $90 \%$ or $80 \%$ of their fatigue life can be greatly improved through the repair experimental study using high voltage pulse discharge. The total fatigue life of the specimens has been extended, at least $160 \%$ of the fatigue life limit. Therefore, the service life of metal fatigue component can be significantly extended by the method of high voltage pulse discharge repairing.

\section{Acknowledgements}

This work was financially supported by the Open Foundation of the State key Laboratory of Nonliner Mechanics, Institute of Mechanics, Chinese Academy of Sciences.

\section{References}

[1] ZHOU Yizhou, ZHOU Benlian, GUO Xiaonan, HE Guanhu, ZHANG Futian. Reversing Effect of Electric Current Pulse on the Damage of 45 Steel, Chinese Journal of Materials Research, Vol.14, 2000,No.1, 29-36

[2] Han jingtao, Zhao gang, Cao qixiang. The repair phenomenon of cracks in 20MnMo steel and its microstructure change. Chinese Journal of Acta Metallurgica Sinica, 1996.vol.32,No.7,213-218

[3] Shen yifu, Zhou benlian, He guanhu,etc. exploration of a new approach to improve fatigue property of materials I-an increased fatigue life of low carbon steel, Chinese journal of material research, 1996.vol.10,no.2:165-166 
[4] XIAO Suhong, GUO Jingdong, WU Shidin, HE Guanhu, LI Shouxin. Recrystallization of Fatigued Copper Single Crystals Under Electropulsing, Chinese journal of Acta Metallurgica Sinica, 2002,vol.38, no.2:161-165

[5] XIAO Shuhong, GUO Jingdong, LI Shouxin. Dislocation Behaviors Under Electropulsing in Fatigued Copper Single Crystals. Chinese Journal of Material Research, 2003.Vol.17, No.3:225-229

[6] LV Baochen, ZHOU Yizhou,WANG Baoquan, GUO Jingdong. Effect of electropulsing on the fatigued heat-rolled 30CrMnSiA steel. Chinese Journal of Material Research, 2003.Vol.17, No.1:15-18

[7] DU Baiping, MA Baotian, LI Nian, ZHU Weidou. Optimization of Repairing Effect for Fatigue Damaged Steel Specimens. Supplement of Chinese Journal of Material Engineering, 2003:207-210

[8] DU Baiping, MA Baotian, LI Nian, ZHU Weidou. Mechanism of Prolonging Life and Effect for Fatigue Damaged Steel Specimens. Chinese Journal of Mechanical Strength, 2006.Vol.28, No.1:40-45

[9] LI YanLi, QIAO ShengRu, LI Yun, ZHANG ChengYu. Investigation of Repairing Fatigue Damage by Direct Current Electropulsing for LY12CZ Aluminum Alloy. Chinese Journal of Mechanical Strength, 2010, vol.32, No.1:105-109

[10] J. Ahmad, Purbolaksono, L.C. Beng. Thermal Fatigue and Corrosion Fatigue in Heat Recovery Area Wall Side Tubes. International Journal of Engineering Failure Analysis. 2010. Vol.17 :334-343.

[11] H.Q. Lin, Y.G. Zhao, Z.M. Gao, L.G. Hana. Effects of pulse current stimulation on the thermal fatigue crack propagation behavior of CHWD steel. International Journal of Materials Science and Engineering A. 478 (2008) 93-100

[12] V.V. Levitin, S.V. Loskutov. The Effect of A Current Pulse on the Fatigue of Titanium Alloy. International Journal of Solid State Communications.131 (2004) 181-183

[13] J.E. Rodriguez-Sanchez, W.D. Dover, F.P. Brennan. Application of Short Repairs for Fatigue Life Extension. International Journal of Fatigue 26 (2004) 413-420 
Applied Mechanics and Materials I

10.4028/www.scientific.net/AMM.275-277

Experimental Study of the Influence on the Residual Fatigue Life of 45 \# Steel Fatigue Damage Specimens

10.4028/www.scientific.net/AMM.275-277.220 